Article

\title{
Fabrication of Au Nanorods by the Oblique Angle Deposition Process for Trace Detection of Methamphetamine with Surface-Enhanced Raman Scattering
}

\author{
Baini Li, Tianran Wang, Qingqing Su, Xuezhong Wu and Peitao Dong * \\ College of Intelligence Science and Technology, National University of Defense Technology, \\ Changsha 410073, China \\ * Correspondence: ptdong@nudt.edu.cn; Tel.: +86-731-8457-3349
}

Received: 5 July 2019; Accepted: 20 August 2019; Published: 29 August 2019

check for updates

\begin{abstract}
Oblique angle deposition (OAD) is a simple, low cost, effective, and maskless nanofabrication process. It can offer a reliable method for the mass fabrication of uniform metal nanorods which can be used as the surface-enhanced Raman scattering (SERS) substrate with an excellent enhancing performance. Up to now, Ag nanorods SERS substrates have been extensively studied. However, $\mathrm{Ag}$ is chemically active and easy to oxidize under atmospheric conditions. Comparatively, Au is chemically stable and has better biocompatibility than Ag. In this paper, we in detail, studied the electromechanical (EM) field distribution simulation, fabrication, and application of Au nanorods (AuNRs) on trace detection of methamphetamine. According to the finite-difference time-domain (FDTD) calculation results, the maximum EM intensity can be obtained with the length of AuNRs to be $800 \mathrm{~nm}$ and the tilting angle of AuNRs to be $71^{\circ}$ respectively. The aligned Au nanorod array substrate was fabricated by the OAD process. The two key process parameters, deposition angle, and deposition rate were optimized by experiments, which were $86^{\circ}$ and $2 \AA / s$, respectively. Using 1,2-bis (4-pyridyl) ethylene (BPE) as the probe molecule, the limit of detection (LOD) was characterized to be $10^{-11} \mathrm{M}$. The AuNRs were also used to detect methamphetamine. The LOD can be down to M (i.e., $14.92 \mathrm{pg} / \mathrm{ml}$ ), which meet the requirements of the on-site rapid detection of the methamphetamine in human urine $(500 \mathrm{ng} / \mathrm{ml})$.
\end{abstract}

Keywords: oblique angle deposition (OAD); surface-enhanced Raman scattering (SERS); methamphetamine; Au nanorods

\section{Introduction}

Surface-enhanced Raman scattering (SERS) has been widely used as a powerful tool for ultrasensitive chemical analysis [1] and bioanalysis [2]. It can be used in the area of food safety [3], environmental monitoring [4], early disease diagnosis [5], drug detection [6], etc. A key role in SERS performances is played by the substrate. Panneerselvam et al. [7] proposed to divide the SERS substrates insto two types: solid substrate, which is mainly made of metallic nanostructures on a solid-state silicon or glass chip and colloidal substrate, which is mainly formed of metal nanoparticles. The preparation process of the colloid substrate is simple and the SERS performance is excellent. However, the size and morphology of the nanoparticles are difficult to control. Furthermore, the nanoparticles are easy to aggregate in the solution. In addition, the metal nanoparticle solution may fail due to long-term storage or vibration. These will result in a non-uniform and non-stable SERS performance and make it difficult for quantitative analysis using the SERS technique. In comparison, the solid-state SERS substrate has better uniformity and repeatability of the size and morphology of the 
nanostructures, which is inherited from the advantages of the fabrication process. These will lead to a better SERS performance; the solid-state SERS substrate also has a long shelf life (1 year at least) [7].

The electrochemically roughened Ag electrode was the first substrate applied to SERS, which had poor SERS efficiency [8]. After that, researchers focused on how to make high-performance SERS solid-state substrates. The comparison of several typical methods is listed in Table 1. Unfortunately, many of previous methods proposed were complex, high cost, and time consuming, which made it difficult for mass production [9]. Porous anodic alumina oxide (AAO) can only control the nanostructure parameters by adjusting the template structure. Thus, the adjustment capability is restricted. The process of nanosphere lithography (NSL) is complicated and difficult to control. Electron beam lithography (EBL) can fabricate more complicated nanostructures, such as nanotubes, which provide the hollow structure to store or transport molecules. However, EBL costs a lot and is time consuming, which is not suitable for mass production. As for the self-assembly method, it is difficult to precisely control the morphology of the ultimate structures. Oblique angle deposition (OAD) is a physical vapor deposition method in which the normal of the substrate surface is at a large oblique angle $\left(>75^{\circ}\right)$ to the moving direction of evaporated atoms. Through making use of the shadowing effect, the OAD can easily fabricate the nanostructure in a maskless manner. The nanorods can be fabricated in only one step. In conclusion, OAD is a very promising SERS substrate fabrication method that features the advantages of easy implementation, more control, low cost, less time consuming, and suitable for mass production.

Table 1. Typical methods to fabricate solid-state surface-enhanced Raman scattering (SERS) substrates.

\begin{tabular}{ccccccc}
\hline Method & SERS & Repeatability & Uniformity & Substrate & \multicolumn{2}{c}{ Preparation } \\
Area & Preparation & Time & Cost \\
\hline AAO [10-12] & high & good & good & wafer-level & short & lower \\
NSL [13-26] & higher & good & good & wafer-level & short & lower \\
EBL [27-29] & high & best & best & small & long & high \\
Self-Assembly [30-37] & high & best & best & wafer-level & short & low \\
OAD [38-40] & higher & best & best & wafer-level & shorter & lower \\
\hline
\end{tabular}

Nobel metals, such as Ag and Au, are highly preferred for SERS substrate fabrication because of their electronic structure, surface morphology, and interactions with target analytes [7]. So far, Au and Ag nanostructure arrays fabricated by OAD have been applied in SERS, extensively. Zhao et al. pioneered the work of preparing AgNRs structure [41-43]. The enhancement factor of AgNRs substrate can reach $10^{8}$. Numerous other groups had optimized the performance of AgNRs substrate by adjusting the process parameters [44-46]. In recent years, more methods based on OAD have been investigated to fabricate novel SERS substrate for improving SERS performance, reducing costs, etc [47]. Singh et al. demonstrated that if AgNRs grew at $140 \mathrm{~K}$, it would get the same length of nanorods as those done at room temperature in a lower deposition time and show greater SERS performance than the substrate made at room temperature [48]. However, Oh et al. got the opposite conclusion that substrates made at higher temperatures had higher SERS enhancements [49]. There is little in the literature that studies this temperature dependence with other nanostructures, such as AuNRs; perhaps this will be a new area that will be expanded on in the near future for higher SERS performance [47]. For fabrication into smaller dimensions with better control, template assisted deposition was investigated. Templates are surfaces with defined surface structures, so when used in OAD, there will be predefined shadowing [47]. Lithography [50], self-assembled nanoparticles [51], and nano-imprinted polymers [52] are typically used for making templates. However, even with the improved order of nanostructures by templates, the SERS reproducibility remains an issue that needs further study [53]. So far, the tilted nanorod substrate is still of great potential for the application to SERS, which is not only high SERS performance, but also one-step deposition process.

The electromagnetic (EM) field distribution simulation, optimization of structure (e.g., rod length), deposition angle, underlying film thickness, and other work of AgNR substrate have been 
fully completed. However, a tricky problem exists that once the AgNRs are exposed to ambient environments. It is susceptible to surface oxidation and contamination. By contrast, Au is more chemically stable than Ag, which can be stored for a long period of time without oxidation [54]. Moreover, Au has a better biocompatibility, which can physically adsorb or chemically bond with DNA or protein. Zhao et al. [55] fabricated SiNRs array and coated with an Au layer by sputtering. The LOD for 1,2-bis (4-pyridyl) ethylene (BPE) was $10^{-7} \mathrm{M}$. Using BPE with the concentration of $10^{-4}$ as a probe molecule, they also found that the Raman signal on Si nanorods with Au coating samples stored under room conditions for 1-3 years remains strong. This proved that $\mathrm{Au}$ is a kind of material that has prolonged shelf time for SERS applications. We can see that the sensitivity of $\mathrm{SiO}_{2} @ \mathrm{Ag}$ NRs needs further improvement, which maybe indicates that the Raman signal enhancing capability of $\mathrm{SiO}_{2}$ cores is not as good as Au or Ag. Yi-Jun Jen at al. utilized one-step glancing angle deposition to fabricate gold and silver nanohelix arrays (NHAs) on smooth glass substrates [56,57] and the substrate was cooled using liquid nitrogen, reducing the temperature of the substrate to be around $-140{ }^{\circ} \mathrm{C}$. This kind of substrate has a high SERS performance, but compared with Nanorod substrate, there is still room for improvement. In contrast, the preparation of nanorods does not require more complicated parameter adjustment and equipment requirements. Therefore, it is well worth fabricating and verifying the SERS performance of AuNRs. At present, there are a few reports on the preparation of tilted AuNRs by the OAD process. Dikovska et al. have reported the Au nanorods substrate fabricated by pulsed laser deposition based on glancing angle deposition [58]. The Au nanorods with average lengths of $50 \sim 70 \mathrm{~nm}$ that have a diameter in the range of 10 20 nm exhibited a SERS enhancement factor of $10^{5}$, which is lower than the best SERS enhancements factor of nanorod, $10^{8}$, reported earlier using oblique angle deposition $[9,59]$. One of the possible reasons says there is no underlayer Au film deposited underneath the AuNRs. Zhao et al. found that underlayer film can probably generate additional hot spots between the film and nanorods, and substantially improve the SERS signal. They improved the enhancement factor of the AgNR substrate by a factor of around $10^{3}$ through depositing underlayer Ag film [60]. Suzuki et al. have reported AuNRs arrays aligned in line by a dynamic oblique deposition technique [54]. The enhancement factor of AuNR arrays is estimated to be $10^{9}$, which is as large as that of the Ag nanorod arrays. Before AuNRs were deposited, the $\mathrm{SiO}_{2}$ template layer should be prepared by the serial bideposition (SBD) technique in advance. Therefore, it is meaningful to study AuNRs that can be deposited in one-step and have a high SERS performance.

To apply the SERS technology into a real-life area is a mission that lots of researchers have made great efforts to accomplish. Amphetamines, represented by methamphetamine, are the most widely used synthetic drugs. The yield and consumption increase year by year. This kind of drug has brought great harm to society, triggered various illegal and criminal activities, which have seriously disturbed public security. The rapid detection of drugs is of great significance for combating crime and suppressing the epidemic of drugs. At present, common methamphetamine detection methods include gas chromatography [61], high-performance liquid chromatography [62], gas chromatography-mass spectrometry [63], enzyme-linked immunosorbent assay [64], and the immunocolloid gold technique [65]. Among them, the first few methods have higher requirements for analysts and equipment, and they are not suitable for on-site testing. The latter two methods require expensive reagents. The LOD of the commercial colloidal gold test paper is $6.7 \times 10^{-6} \mathrm{M}$. Sometimes false positive signals may be given. There is an urgent need for a reliable on-site rapid detection technology for amphetamines. SERS is a highly sensitive sensing technology with a single molecule "fingerprint" identification capability. With the development of portable Raman spectroscopy, SERS technology can play an important role in the field of drug detection.

In this work, aligned AuNRs arrays have been successfully fabricated for surface-enhanced Raman scattering based on OAD process. The EM filed distribution of AuNRs arrays was visualized via FDTD calculation. The length and tilting angle of AuNRs were optimized. On the basis of SEM images, the relationship between process parameters and structure parameters has been discussed for guiding the process. SERS performance was validated using BPE as the probe molecule. The LOD can reach 
$10^{-11} \mathrm{M}$. We tested methamphetamine with the AuNRs substrate. The LOD can reach $10^{-7} \mathrm{M}$ (i.e., $14.92 \mathrm{pg} / \mathrm{ml}$ ), which met the requirements for the on-site rapid detection of the methamphetamine in human urine $(500 \mathrm{ng} / \mathrm{ml})$. This is better than the LOD of the commercial colloidal gold test paper, i.e., $10^{-6} \mathrm{M}$. The AuNRs substrate provides a good platform for trace biochemical detection based on SERS.

\section{Materials and Methods}

\subsection{Materials}

1,2-bis (4-pyridyl) ethylene (BPE) was purchased from Sigma-Aldrich., USA. Silicon wafer purchased from the 42nd Institute of the fourth Academy of CASC was used as the deposition substrate. Gold $(\mathrm{Au})$ pellets with the purity of $99.99 \%$ and chromium $(\mathrm{Cr})$ pellets with the purity of $99.999 \%$ were purchased from Jinyu Aochen (Beijing, China). Ethanol $\left(\mathrm{C}_{2} \mathrm{H}_{5} \mathrm{OH}\right)$, sulfuric acid $\left(\mathrm{H}_{2} \mathrm{SO}_{4}\right)$ and hydrogen peroxide solution $\left(\mathrm{H}_{2} \mathrm{O}_{2}\right)$ were purchased from Sinopharm (Shanghai, China). Twice distilled water (resistance rate $\geq 18.2 \mathrm{M} \Omega \cdot \mathrm{cm}$ ) was used as the water sample.

\subsection{Apparatus}

AuNRs array was deposited on the cleaned silicon substrate in a custom modified e-beam evaporator (ZZS500, Nanguang, Chengdu, China). The Raman spectra were collected with a portable Raman system equipped with a $785 \mathrm{~nm}$ excitation source and the laser spot diameter was 106 (BWS415-785S, from B\&W, Tek, Newark, DE, USA). The field-emission SEM (S-4800, Hitachi, Tokyo, Japan) was used to analyze the morphology of the film.

\subsection{FDTD Modeling}

FDTD (finite-difference time-domain) software was utilized to visualize the electromagnetic characteristic of the AuNRs. The simulation model was constructed using the 3D modeling function of the software, as shown in Figure 1. The Z-axis direction was defined as surface normal of the substrate. $Y$-axis direction was defined to be perpendicular to Z-axis direction and along the growing direction of AuNRs. X-axis direction was perpendicular to both Y-axis and Z-axis direction.

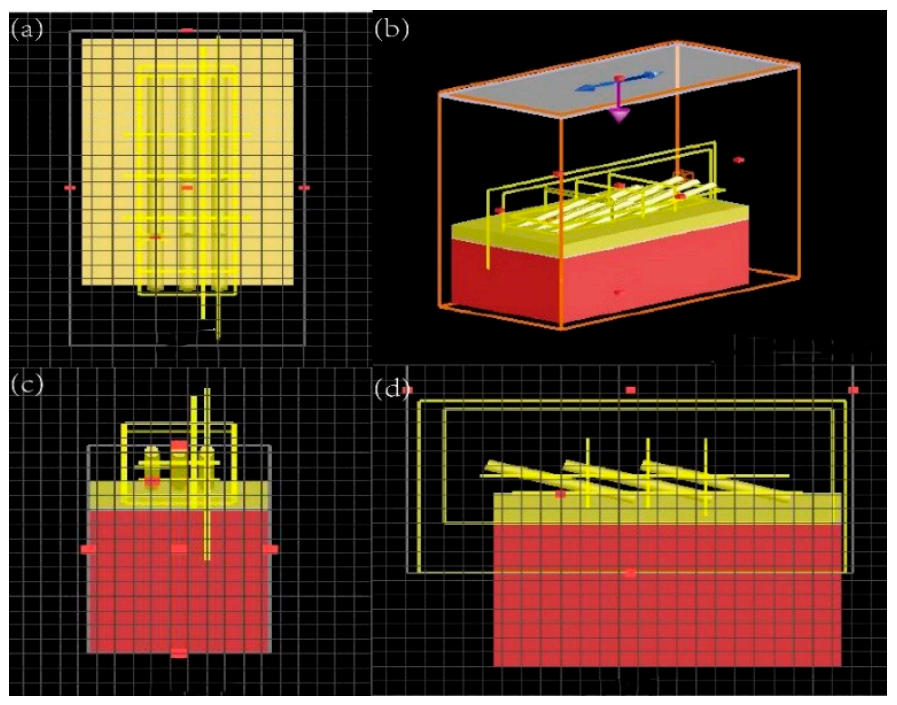

Figure 1. Models of Au nanorods (AuNRs) for finite-difference time-domain (FDTD) simulation: (a) $\mathrm{XY}$ plane, (b) oblique view, (c) XZ plane, (d) YZ plane.

The size of the Si substrate model was $1000 \mathrm{~nm} \times 1800 \mathrm{~nm}$. The bottom layer of $\mathrm{Cr}$ on the Si substrate was $20 \mathrm{~nm}$ thick, and the layer of $\mathrm{Au}$ on the $\mathrm{Cr}$ was $100 \mathrm{~nm}$ thick. The Au nanorod distributed regularly on the Au layer. The length of AuNRs, L, was set to be 400, 600, 800, 1000, and $1200 \mathrm{~nm}$ and 
the tilting angle $\beta$ was set to be $67^{\circ}, 69^{\circ}, 71^{\circ}, 73^{\circ}, 75^{\circ}$, and $77^{\circ}$, respectively. In order to simplify the model, only three rows and three columns of AuNRs were employed, the distance between two NRs along the $X$-axis was $550 \mathrm{~nm}$ and $150 \mathrm{~nm}$ along the $Y$-axis. The meshes were set with the cell size of $2 \mathrm{~nm} \times 2 \mathrm{~nm} \times 2 \mathrm{~nm}$. The perfectly matched layer absorbing boundary conditions were adopted in the X, Y, Z-direction. The plane wave with a wavelength of $785 \mathrm{~nm}$ was utilized as the laser source which was normally incident to the substrate with the polarization parallel to the $\mathrm{X}$-direction.

\subsection{Preparation of AuNRs Substrate}

The AuNRs substrate was fabricated by the OAD method. The schematic of the process is shown in Figure 2a. The deposition angle $\theta$ is defined as the angle between the substrate surface normal and vapor flux direction. Before deposition, all glass slides with a typical dimension of $10 \mathrm{~mm} \times 10 \mathrm{~mm}$ and silicon (100) substrates with a typical dimension of $5 \mathrm{~mm} \times 5 \mathrm{~mm}$ were cleaned in the Piranha solution, then rinsed with deionized water for three times and dried by nitrogen. A thin layer of $20 \mathrm{~nm}$ $\mathrm{Cr}$ was firstly deposited onto the cleaned substrate with deposition angle $\theta$ at $0^{\circ}$. The purpose of this step is to increase the adhesion of the gold film to substrate. Secondly, a plain layer of $100 \mathrm{~nm}$ Au was deposited onto the $\mathrm{Cr}$ thin film in order to enhance the adsorption of the columnar structure on the surface. This also can enhance the SERS performance of the AuNRs structure. Thirdly, AuNRs were prepared by the OAD technique with a big deposition angle (usually $\theta>75^{\circ}$ ). During deposition, the thickness of the deposited film was monitored by a quartz crystal microbalance (QCM) positioned near the substrate. The pressure in the vacuum chamber was around $4 \times 10^{-4} \mathrm{~Pa}$. The deposition angle and deposition rate are the two key process parameters. By adjusting these two parameters, AuNRs with different structures can be obtained. Several deposition angles, $\theta=80^{\circ}, 82^{\circ}, 84^{\circ}, 86^{\circ}$, and $88^{\circ}$, and several deposition rates, $\mathrm{v}=1,2,3 \AA$ /s have been adopted during experiments in order to find the optimized process parameters.

(a)

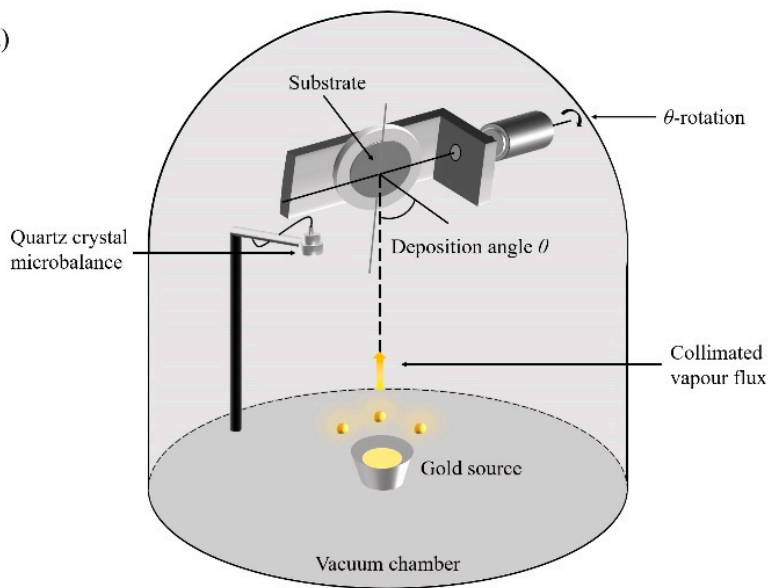

(b)

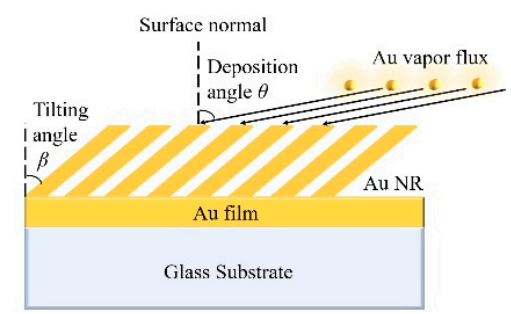

Figure 2. (a) The schematic of the Oblique Angle Deposition (OAD) process. (b) The schematic of the AuNRs structure. The definition of the deposition angle $\theta$ and the tilting angle $\beta$ is shown.

Figure $2 b$ shows the schematic of the fabricated AuNRs. The definition of the deposition angle $\theta$ and the tilting angle of AuNRs, $\beta$, are given. The principle of OAD is the shadowing effect during evaporation [66]. As shown in Figure $2 b, \beta$ is always smaller than $\theta$. The growth dynamics will determine the relationship between $\beta$ and $\theta$. This is also one of the important topics which this paper will talk about in detail.

\subsection{Raman Measurements}

Raman spectra were collected with the Raman microscope (innoRam, B\&W Tek. Inc., Newark, DE, USA) equipped with a $785 \mathrm{~nm}$ laser source. Spectra were obtained for $10 \mathrm{~s}$ integration time, and the 
laser power was about $90 \mathrm{~mW}$. The curves presented here were drawn according to the dark subtracted data and for the average from nine randomly chosen spots of a given substrate. BPE was chosen to be the probe molecule to characterize the SERS enhancement ability of the AuNRs.

\section{Results and Discussion}

\subsection{FDTD Calculation}

In order to demonstrate the effect of the tilting angle and length of the AuNRs, the distributions of the electromechanical field were visualized by the FDTD calculation. The model and simulation parameters are described in Section 2.3. The results of the calculation were shown in Figures 3 and 4.
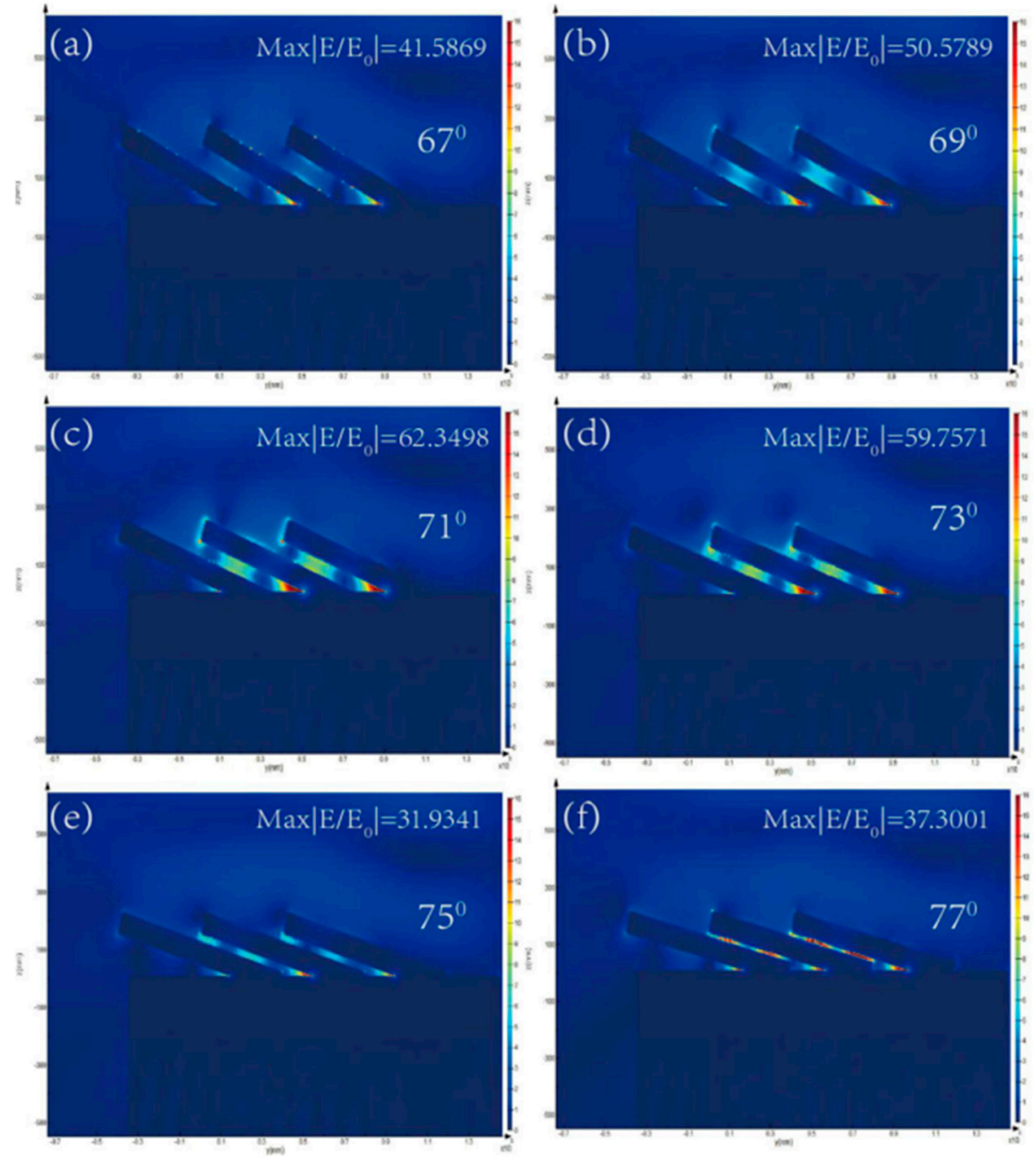

Figure 3. Calculation results of the AuNRs array with different tilting angles by the FDTD method: (a) $\beta=67^{\circ}$; (b) $\beta=69^{\circ}$; (c) $\beta=71^{\circ}$; (d) $\beta=73^{\circ}$; (e) $\beta=75^{\circ}$; (f) $\beta=77^{\circ}$. 

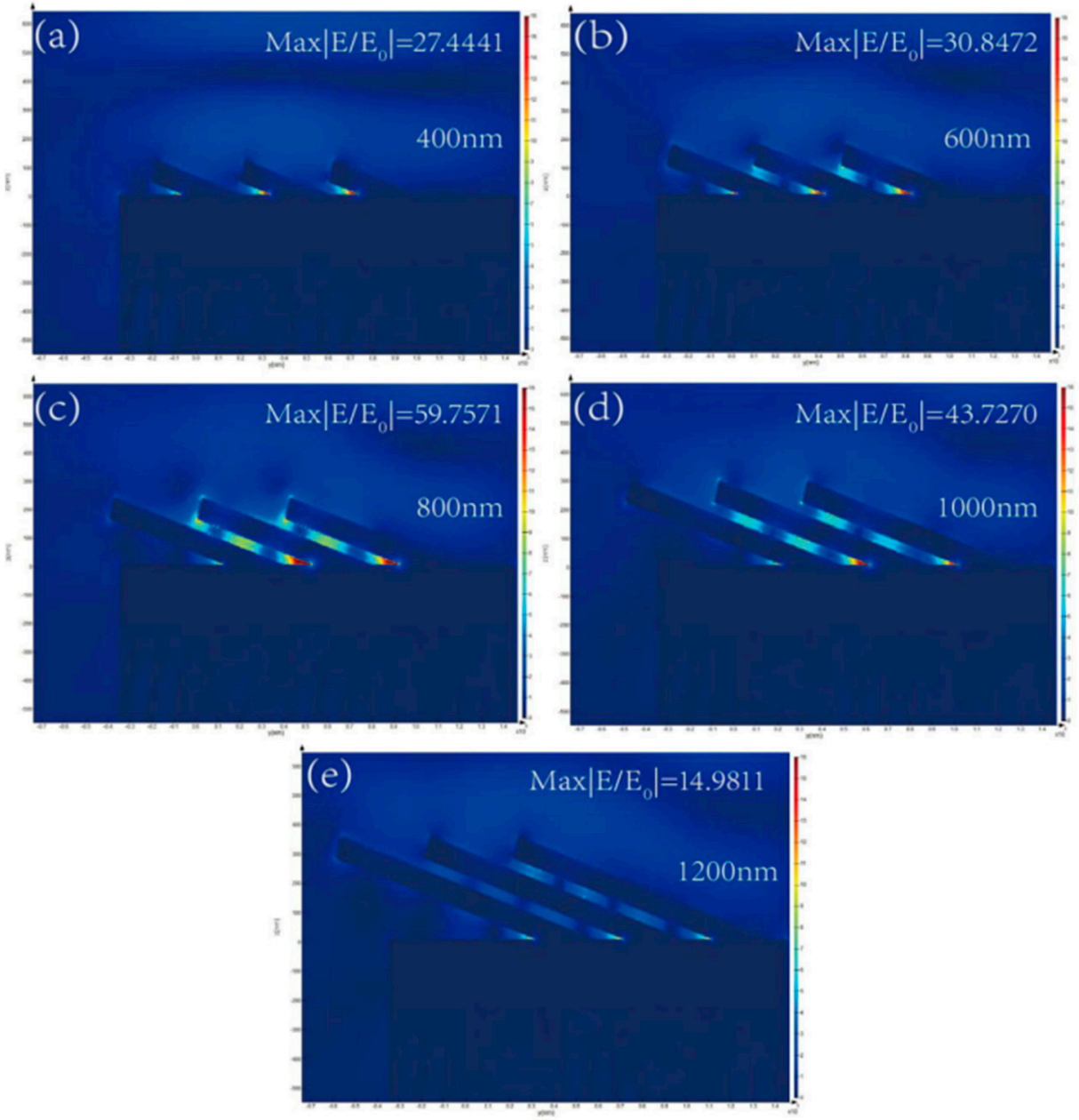

Figure 4. Calculation results of the AuNRs array with different lengths by the FDTD method: (a) $\mathrm{L}=$ $400 \mathrm{~nm}$; (b) L = $600 \mathrm{~nm}$; (c) L = $800 \mathrm{~nm}$; (d) L = $1000 \mathrm{~nm}$; (e) L = $1200 \mathrm{~nm}$.

Figure 3 shows the electromagnetic (EM) field distribution of the AuNRs array at different tilting angles. The EM field distributions are similar except for the magnitude of intensities. The "hotspots" are located at the connective position between AuNRs and the underlying Au film, the tip of nanorods and the gaps between the adjacent AuNRs. However, intensities of the "hotspots" vary with the different tilting angles. For tilting angle $\beta=67^{\circ}, 69^{\circ}, 71^{\circ}, 73^{\circ}, 75^{\circ}$, and $77^{\circ}$, the corresponding electromagnetic field intensity $\left|\mathrm{E} / \mathrm{E}_{0}\right|$ is $41.5869,50.5789,62.3498,59.7571,31.9341$, and 37.3001 . Figure 5 plots the electromagnetic field intensity of the Au nanorod array as the function of the tilting angle. With tilting angle of AuNRs increased from $67^{\circ}$ to $71^{\circ}$, the electromagnetic field intensity gradually enhances. As the tilting angle increased from $71^{\circ}$ to $77^{\circ}$, the electromagnetic field intensity gradually decreases. Considering the comprehensive factors, such as process and manufacturing cost, the tilting angle of the Au nanorod is optimized to be $71^{\circ}$. 


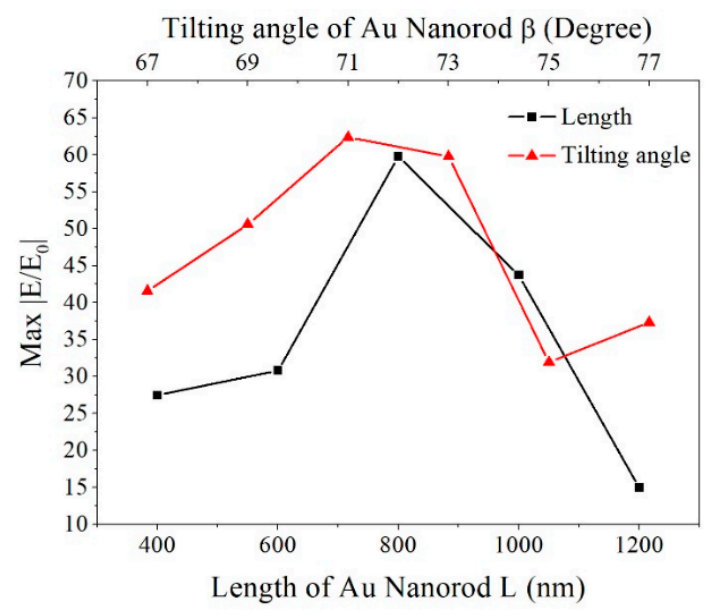

Figure 5. The electromagnetic field intensity as a function of AuNRs length and tilting angle.

Figure 4 shows the EM field distribution of the AuNRs array with different length. The "hotspots" distributions are also located at the same location as the simulation results shown in Figure 4. Intensities of the "hotspots" vary with different length of AuNRs. For length $\mathrm{L}=400,600,800,1000$, and 1200 $\mathrm{nm}$, the corresponding electromagnetic field intensity $\left|\mathrm{E} / \mathrm{E}_{0}\right|$ is $27.4441,30.8472,59.7571,43.7270$, and 14.9811 , respectively. The electromagnetic field intensity of the Au nanorod array as the function of the length is also plotted in Figure 5. With the length of AuNRs increased from $400 \mathrm{~nm}$ to $800 \mathrm{~nm}$, the electromagnetic field intensity gradually enhances. As length increased from $800 \mathrm{~nm}$ to $1200 \mathrm{~nm}$, the electromagnetic field intensity gradually decreases. The electromagnetic field intensity reaches the maximum as the length of AuNRs is $800 \mathrm{~nm}$. Also considering the comprehensive factors such as process and manufacturing cost, the length of the Au nanorod is optimized to be $800 \mathrm{~nm}$.

\subsection{Morphological Characterizations of Au Nanorod}

Top-view and cross-section SEM images of five representative Au nanorod arrays fabricated at deposition angle $\theta=80^{\circ}, 82^{\circ}, 84^{\circ}, 86^{\circ}$, and $88^{\circ}$ are shown in Figure 6. In all experiments in this section, film thicknesses recorded by QCM were adjusted to make the length of AuNRs to be $800 \mathrm{~nm}$. The deposition rates were all set to be $1 \AA$ /s. In Figure 6, we can see some nuances of morphologies of the five fabricated nanostructures. For small deposition angle, 80 and $82^{\circ}$, the Au nanorods tightly pack and fuse together. The diameter of the AuNRs is large and the distance between nanorods is small. With $\theta$ increased $\left(\theta=84,86\right.$ and $\left.88^{\circ}\right)$, the gap between Au nanorods also increases. Hence the density decreases. The nanorod tilting angle $\beta$ can be measured from the cross-section SEM images. Average tilting angles of five groups of nanorods with different deposition angles are shown in Figure 7 . For $\theta=80^{\circ}, 82^{\circ}, 84^{\circ}, 86^{\circ}$ and $88^{\circ}$, the corresponding tilting angle $\beta$ are $59.9 \pm 4.5,64.2 \pm 2.5,68.9 \pm 2.5$, $70.8 \pm 2.3,72.4 \pm 1.4^{\circ}$, respectively. The tilting angle $\beta$ is always less than the deposition angle $\theta$ and increases with $\theta$ increased. The relationship between the tilting angle $\beta$ and deposition angle $\theta$ is plotted in Figure 7. 

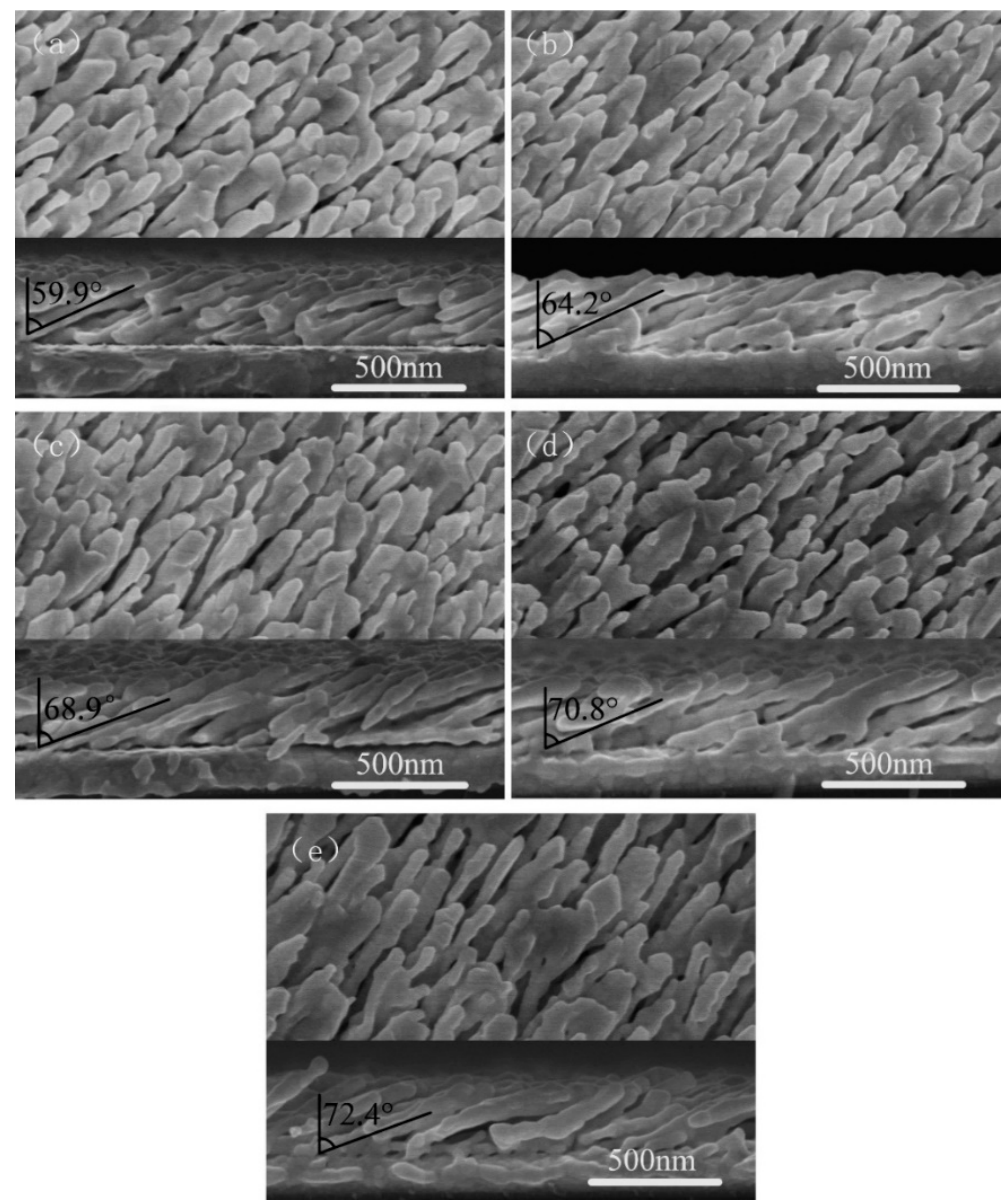

Figure 6. The SEM images of AuNRs deposited at different deposition angle $\theta:(\mathbf{a}) \theta=80^{\circ},(\mathbf{b}) \theta=82^{\circ}$, (c) $\theta=84^{\circ}$, (d) $\theta=86^{\circ}$, (e) $\theta=88^{\circ}$. The upper part of each image is the top-view and the lower part is the cross-section view.

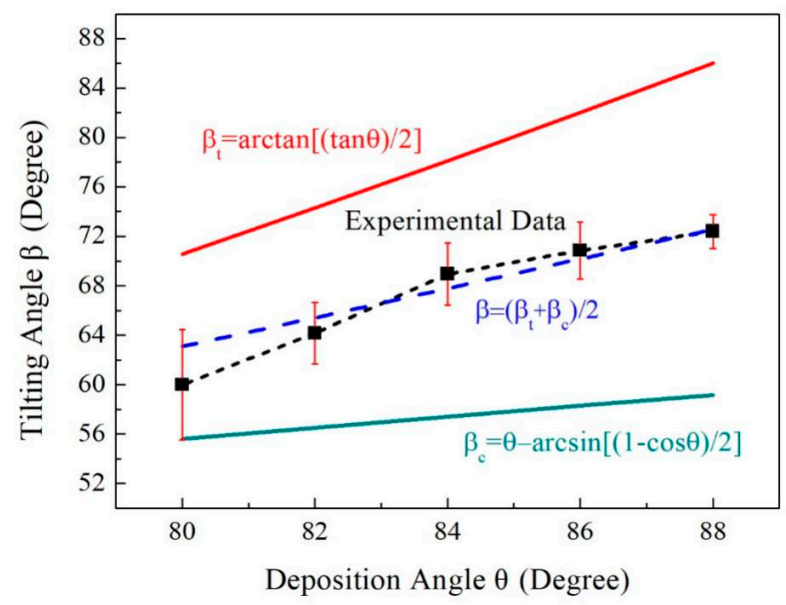

Figure 7. The Au nanorod tilting angle $\beta$ as a function of deposition angle $\theta$.

Different models describing the relationships between the tilting angle $\beta$ and deposition angle $\theta$ have been proposed in the literature. The simplest and earliest relationship is the tangent rule, $\beta_{\operatorname{tangent}}=\arctan (1 / 2 \tan \theta)$, which is plotted using a red solid line in Figure 7 . However, the tangent rule is not derived from a physical model and tends to overestimate $\beta$ at a large deposition angle $\theta$ [67]. The relationship expressed by cosine rule, $\beta_{\operatorname{cosine}}=\theta-\arcsin [(1-\cos \theta) / 2]$, which is proposed based on geometric analysis [67], is plotted using the green solid line in Figure 7. The nanorod tilting angles 
predicted by cosine rule underestimate the true value. As shown in Figure 7, the true value is close to the average of angles calculated by tangent rule and cosine rule, i.e., $\beta=\left(\beta_{\text {tangent }}+\beta_{\text {cosine }}\right) / 2$, which is plotted in blue dashed line. This conclusion is consistent with the study of the previous literature [41]. The average diameters of nanorods are $\mathrm{d}=82 \pm 11,74 \pm 10,67 \pm 9,62 \pm 7,60 \pm 7 \mathrm{~nm}$ and the densities are $51 \pm 3,49 \pm 2,46 \pm 3,42 \pm 3,37 \pm 3$ rods/ $\mu \mathrm{m}^{2}$, respectively. Figure 8 plots the density and the diameter of the Au nanorod as the function of the deposition angle $\theta$. This trend is monotonic. The density and diameter will decrease as $\theta$ increased. Because of the increased deposition angle, the shadow effect will play a more important role during the evaporation. Hence the intercolumn void region expands, creating more room between columns and correspondingly reducing the density of the Au nanorods [66].

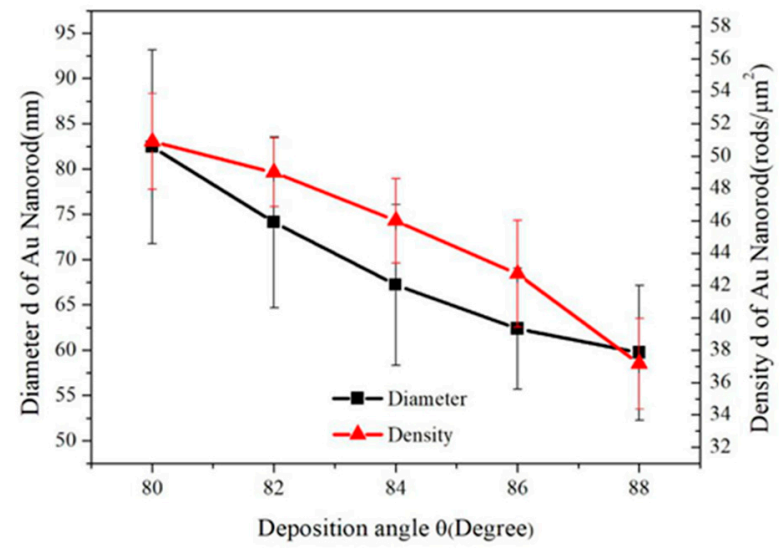

Figure 8. The plot of Au nanorod diameter and density vs. the deposition angle $\theta$.

SEM images of another three groups of Au nanorods are shown in Figure 9. The deposition rates are 1, 2, $3 \AA / s$, respectively. Film thicknesses recorded by QCM were adjusted to make the length of AuNRs to be $800 \mathrm{~nm}$. The deposition angles $\theta$ are $86^{\circ}$. The density monotonically increases as the deposition rate increased. The average densities are $43 \mathrm{rods} / \mu \mathrm{m}^{2}, 58 \mathrm{rods} / \mu \mathrm{m}^{2}, 132 \mathrm{rods} / \mu \mathrm{m}^{2}$ for deposition rate $\mathrm{R}=1,2,3 \AA / \mathrm{s}$. For a small deposition rate $(\mathrm{R}=1 \AA \mathrm{A} / \mathrm{s}, 2 \AA / \mathrm{s})$, the gap distances between columns are $320 \mathrm{~nm}$ and $249 \mathrm{~nm}$ respectively. At these two deposition rates, rods are separated by void region due to the shadowing effect. For a fast deposition rate $(R=3 \AA / s)$, the distance between columns is $105 \mathrm{~nm}$, nanorods tightly pack with very small void regions. This result is also observed in ref. [68].
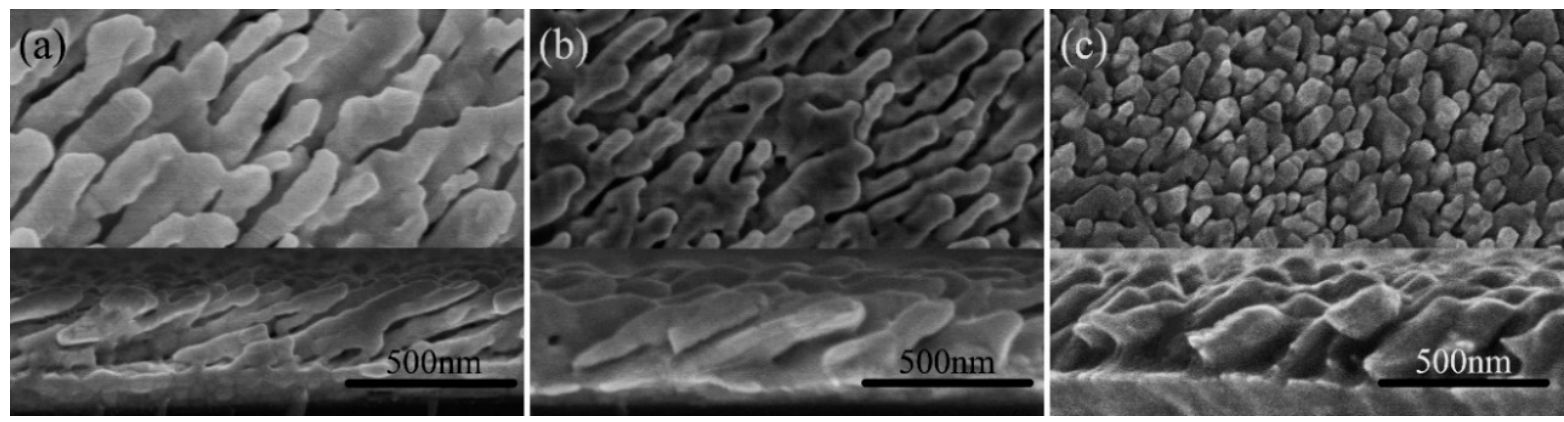

Figure 9. The SEM images of AuNRs deposited at different deposition rate $R$ : (a) $R=1 \AA / s,(b) R=2 \AA / s$, (c) $\mathrm{R}=3 \AA / \mathrm{s}$.

\subsection{SERS Performance Characterization}

To obtain the SERS enhancement ability of the AuNRs, the Raman spectra were acquired using $\mathrm{BPE}$ as the probe molecule. A series of concentrations of BPE ethanol solution ranging from to was prepared. BPE solution was dropped on the AuNRs substrates. Then the substrates were dried in atmospheric circumstance prior to measurement. 
Figure 10 shows the average SERS spectra of BPE detected on the AuNRs array substrates deposited at $\theta=80^{\circ}, 82^{\circ}, 84^{\circ}, 86^{\circ}$ and $88^{\circ}$, respectively. All the SERS spectra show three characteristic peaks of BPE [69] listed in Table 2: ( $\mathrm{C}=\mathrm{C}$ stretching mode), (aromatic ring stretching mode) and (in-plane ring mode). Among the five substrates shown in Figure 6, the best LOD, $10^{-9} \mathrm{M}$, can be obtained for the nanostructures fabricated at deposition angle.

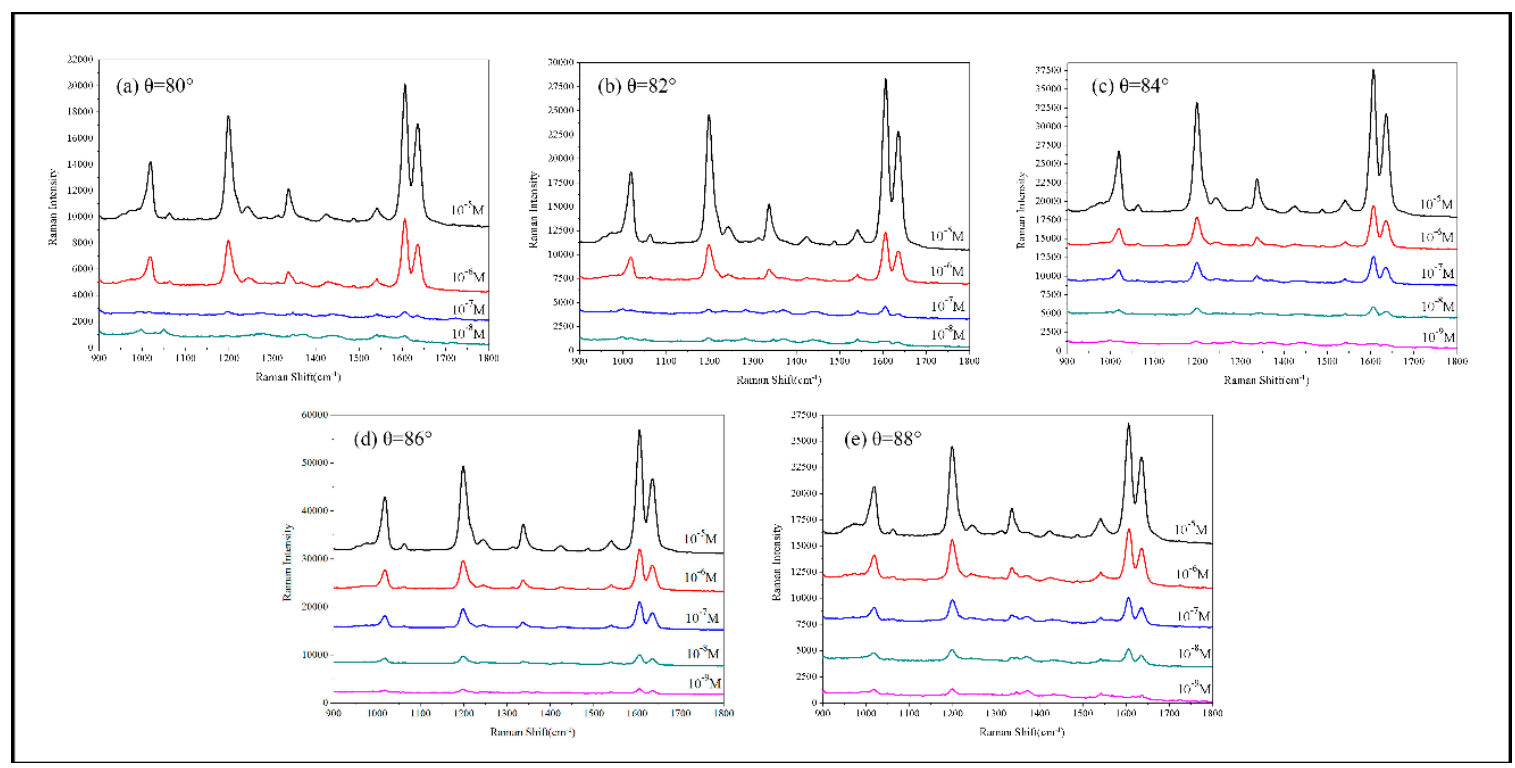

Figure 10. SERS spectra of BPE detected on the AuNRs substrates fabricated at different deposition angle: (a) $\theta=80^{\circ}$; (b) $\theta=82^{\circ}$; (c) $\theta=84^{\circ}$; (d) $\theta=86^{\circ}$; (e) $\theta=88^{\circ}$.

Table 2. Assignments of SERS bands of BPE.

\begin{tabular}{cc}
\hline Wavenumber $\left(\mathbf{c m}^{\mathbf{- 1}}\right)$ & Assignments of SERS Bands \\
\hline 1198 & C-C Stretch \\
1605 & Aromatic ring stretching \\
1637 & in-plane ring \\
\hline
\end{tabular}

Figure 11 shows the SERS spectra of BPE detected on the AuNRs array substrates shown in Figure 9. Among these three substrates, the best LOD, $10^{-11} \mathrm{M}$, can be obtained with structures fabricated at deposition rate $2 \AA / s$.
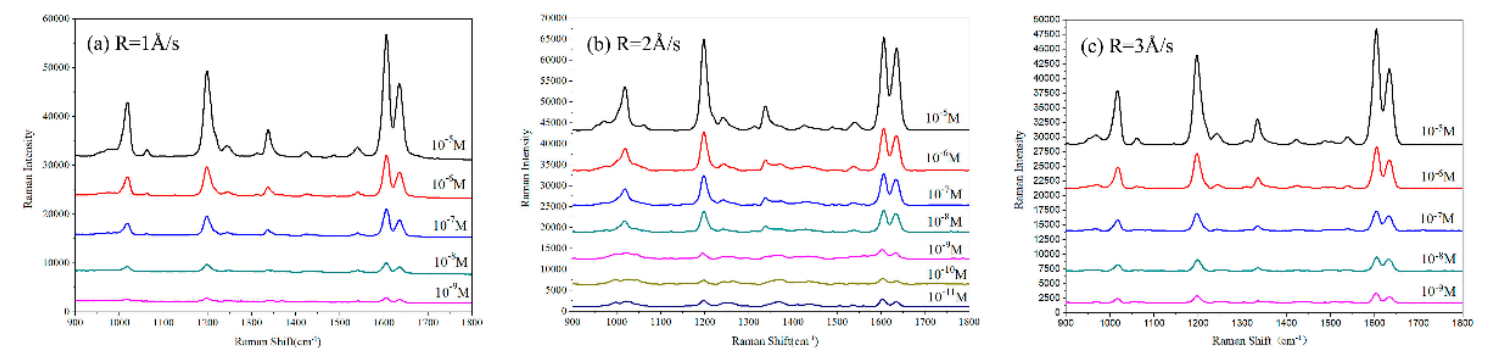

Figure 11. SERS spectra of BPE detected on the AuNRs substrates fabricated with different deposition rate: (a) $\mathrm{R}=1 \AA / \mathrm{s}$; (b) $\mathrm{R}=2 \AA / \mathrm{s}$; (c) $\mathrm{R}=3 \AA$ s.

In order to quantitatively compare the AuNRs substrates deposited at different deposition angles and deposition rates, the SERS peak at $\Delta v=1197.9 \mathrm{~cm}^{-1}$ and the equation 
$\mathrm{EF}=\left(\mathrm{I}_{\mathrm{SERS}} / \mathrm{I}_{\mathrm{RS}}\right) \times\left(\mathrm{N}_{\mathrm{Vol}} / \mathrm{N}_{\text {Surf }}\right)[70]$ were used to estimate the SERS enhancement factor $(\mathrm{EF})$, where $\mathrm{N}_{\text {Surf }}=\mathrm{C}_{\text {SERS }} \mathrm{V}_{\text {SERS }} \times\left(\mathrm{S}_{\text {laser }} / \mathrm{S}_{\text {SERS }}\right) \times \mathrm{N}_{\mathrm{A}}$ is the estimated number of absorbed molecules in the scattering volume for the SERS detection and $\mathrm{N}_{\mathrm{Vol}}=\mathrm{C}_{\mathrm{RS}} \mathrm{V}_{\text {Laser }} \mathrm{N}_{\mathrm{A}}$ is the estimated number of molecules in the scattering volume for the Raman (non-SERS) measurement. In our experiment, the normal Raman peak intensity of $C_{R S}=10^{-2} \mathrm{M}$ BPE solution at $\Delta v=1197.9 \mathrm{~cm}^{-1}$ was $\mathrm{I}_{\mathrm{RS}}=32$ counts. The volume of BPE solution producing Raman scattering was calculated to be $\mathrm{V}_{\text {Laser }}=2.8 \times 10^{-12} \mathrm{~m}^{3}$ [71] and thus, the amount of molecules excited in normal Raman measurement was estimated as $\mathrm{N}_{\mathrm{Vol}}=1.69 \times 10^{10}$ $\left(\mathrm{N}_{\mathrm{A}}=6.02 \times 10^{23} \mathrm{~mol}^{-1}\right.$ is the Avogadro constant). In SERS measurement, $\mathrm{V}_{\mathrm{SERS}}=2 \mu \mathrm{l} \mathrm{BPE}$ solution which concentration is $C_{\text {SERS }}=10^{-6} \mathrm{M}$ was dispersed onto the AuNRs substrate. In the actual experiment, the $2 \mu \mathrm{BPE}$ droplet is in fact spread over the entire $1 \times 1 \mathrm{~cm}^{2}$ substrate, so $S_{\text {SERS }}=1 \times 10^{-4} \mathrm{~m}^{2}$. The laser spot diameter is $106 \mu \mathrm{m}$ and then the laser beam area $S_{\text {laser }}=\pi \mathrm{r}^{2}=3.53 \times 10^{-12} \mathrm{~m}^{2}$ on the substrate can be calculated. For different deposition angles $\theta=80,82,84,86$ and $88^{\circ}$, the ISERS $=3300$, $3730,3862,6079$ and 3953 counts, and $\mathrm{EF}=4.10 \times 10^{7}, 4.62 \times 10^{7}, 4.79 \times 10^{7}, 7.53 \times 10^{7}$ and $4.90 \times 10^{7}$, respectively. The EF first increases with the deposition angle, reaches a maximum at the optimum deposition angle $\theta=86^{\circ}$, and then decreases with further increase of deposition angle. For different deposition rates $\mathrm{R}=1,2,3 \AA \mathrm{A} / \mathrm{s}$, the $\mathrm{I}_{\mathrm{SERS}}=6079,9239$ and 5838 counts, and $\mathrm{EF}=7.53 \times 10^{7}, 1.22 \times 10^{8}$ and $7.24 \times 10^{7}$. The computed results show that the EF reaches a maximum value when AuNRs substrate deposited at deposition angle $\theta=86^{\circ}, \mathrm{R}=2 \AA / \mathrm{s}$.

Summarizing all the above-mentioned experiment data, we can get a conclusion that the best SERS enhancement performance can be obtained with the AuNRs deposited at angle $86^{\circ}$ with rate $2 \AA / s$. The length of the AuNRs should be $800 \mathrm{~nm}$.

\subsection{SERS Detection of Methamphetamine}

We chose the most sensitive AuNRs substrate with a length of $800 \mathrm{~nm}$ deposited at angle $\theta=86^{\circ}$ and rate $R=2 \AA / s$ to detect methamphetamine. We first prepared a series of concentrations of methamphetamine solution ranging from $10^{-3} \mathrm{M}$ to $10^{-7} \mathrm{M}$. $2 \mu$ methamphetamine solution were dropped on the AuNRs substrates. Then the substrates were dried in atmospheric circumstance prior to measurement.

The characteristic peaks of methamphetamine are shown in Table 3. $\Delta v=620 \mathrm{~cm}^{-1}, \Delta v=1001 \mathrm{~cm}^{-1}$, $\Delta v=1021 \mathrm{~cm}^{-1}$ are attributed to the breathing vibration of the benzene ring. $\Delta v=1208 \mathrm{~cm}^{-1}$ is attributed to the phenyl-C stretching mode. $\Delta v=1582 \mathrm{~cm}^{-1}, \Delta v=1601 \mathrm{~cm}^{-1}$ are attributed to the stretching of the benzene ring. $\Delta v=835 \mathrm{~cm}^{-1}$ is attributed to the stretching vibration mode of isopropyl C-C. The spectra of different concentration detected are shown in Figure 12a. Among them, the characteristic peak of $1001 \mathrm{~cm}^{-1}$ has the highest intensity and is easier to be recognized. Therefore, the characteristic peak of $1001 \mathrm{~cm}^{-1}$ is taken as a reference to study the variation of SERS signal intensity with the concentration of methamphetamine. Figure $12 \mathrm{~b}$ shows the detailed changes in the SERS spectrum from $990 \mathrm{~cm}^{-1}$ to $1015 \mathrm{~cm}^{-1}$. As the concentration of methamphetamine decreased from $10^{-1} \mathrm{M}$ to $10^{-7} \mathrm{M}$, the Raman intensity of the characteristic peak gradually decreases. The LOD is characterized to be $10^{-7} \mathrm{M}(14.92 \mathrm{pg} / \mathrm{ml})$, which meet the requirements of the on-site rapid detection of the methamphetamine in human urine $(500 \mathrm{ng} / \mathrm{ml})$. This is better than the LOD of the commercial colloidal gold test paper, i.e., $10^{-6} \mathrm{M}$. Moreover, the collection of SERS spectrum is seconds response. From sample preparation to test and then data analysis, the whole detection time was less than $5 \mathrm{~min}$. 
Table 3. Assignments of SERS bands of methamphetamine.

\begin{tabular}{|c|c|c|}
\hline Assignments of SERS Bands & $\begin{array}{c}\text { Literature Report } \\
\text { Wavenumber }[72,73]\left(\mathrm{cm}^{-1}\right)\end{array}$ & $\begin{array}{l}\text { Experimental Data } \\
\qquad\left(\mathrm{cm}^{-1}\right)\end{array}$ \\
\hline the breathing vibration of the benzene ring & 620 & 618 \\
\hline the stretching vibration mode of isopropyl C-C & 834 & 835 \\
\hline the breathing vibration of the benzene ring & 1001 & 1001 \\
\hline the breathing vibration of the benzene ring & 1023 & 1027 \\
\hline the phenyl-C stretching mode & 1207 & 1204 \\
\hline the phenyl-C stretching mode & & 1212 \\
\hline the stretching of benzene ring & 1583 & 1580 \\
\hline the stretching of benzene ring & 1601 & 1605 \\
\hline
\end{tabular}

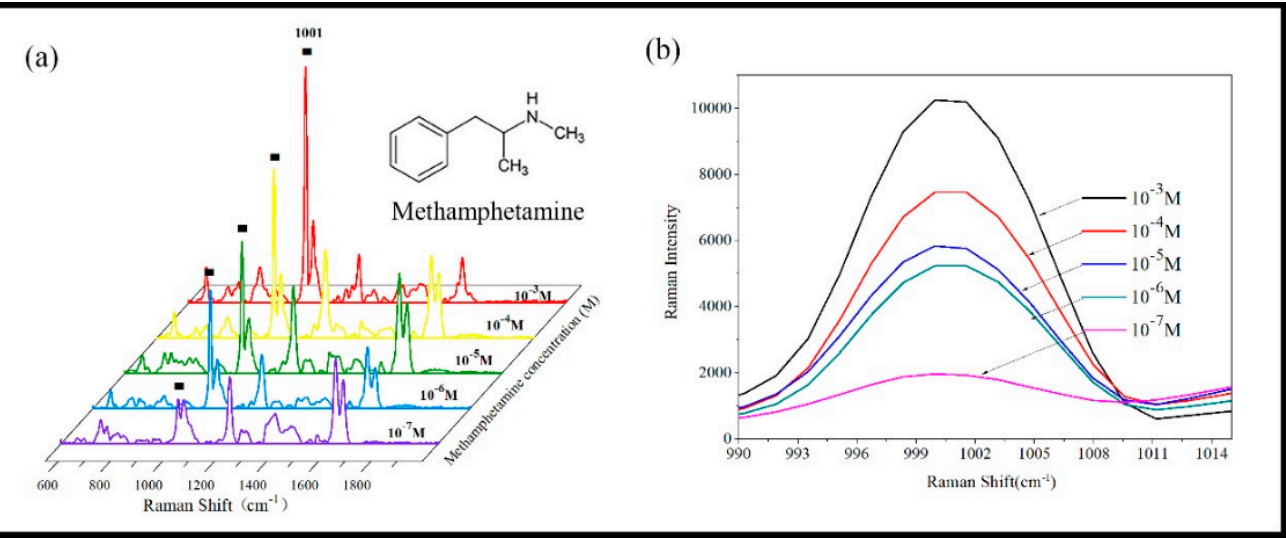

Figure 12. (a) The SERS spectra of AuNRs arrays substrate measured with various of methamphetamine; (b) the drawing of partial enlargement at the vibration bands of $1001 \mathrm{~cm}^{-1}$.

\section{Conclusions}

OAD is a very promising nanofabrication technique, which has the advantage of easy implementation, low cost, with no need for nanopattern, etc. To overcome the shortcomings of AgNRs as SERS substrate, such as easy to be oxidized and contaminated, we have proposed to fabricate AuNRs by the OAD process. FDTD simulation results show that, to obtain a maximum EM intensity, the optimized tilting angle of AuNRs should be $71^{\circ}$ and the length should be $800 \mathrm{~nm}$. SEM images show that tilting angle of AuNRs increased with the increase of the deposition angle from $80^{\circ}$ to $88^{\circ}$, meanwhile, the diameter and density decrease. AuNRs with the tilting angle of $71^{\circ}$ can be fabricated at deposition angle of $86^{\circ}$. When deposited at different deposition rates, the density of AuNRs increased with the increase of the deposition rate from $1 \AA / s$ to $3 \AA / s$. Raman enhancement capability was validated by SERS measurement using BPE as the probe molecule. The best LOD was characterized to be $10^{-11} \mathrm{M}$ using the substrate with length of $800 \mathrm{~nm}$, which was fabricated at a deposition angle of $86^{\circ}$ and deposition rate of $2 \AA / s$. This substrate was also used for the trace detection for methamphetamine. The LOD can reach $10^{-7} \mathrm{M}(14.92 \mathrm{pg} / \mathrm{ml})$, which meets the requirements of on-site rapid detection of methamphetamine in human urine $(500 \mathrm{ng} / \mathrm{ml})$. This result is better than the LOD of the commercial colloidal gold test paper, i.e., $10^{-6} \mathrm{M}$. Characterization results have shown that AuNRs fabricated by $\mathrm{OAD}$ is a very promising SERS substrate for trace analyte detection and bio-sensing.

Author Contributions: Conceptualization, P.D. and X.W.; methodology, P.D.; validation, B.L., T.W., and Q.S.; formal analysis, B.L.; data curation, T.W.; writing—original draft preparation, B.L. and P.D.; supervision, P.D.; project administration, P.D.; funding acquisition, P.D. and X.W.

Funding: This research was funded by the National Natural Science Foundation of China (No.51475468 and 51605486)

Conflicts of Interest: The authors declare no conflict of interest. 


\section{References}

1. Wang, X.T.; Shi, W.S.; She, G.W.; Mu, L.X.; Lee, S.T. High-performance surface-enhanced Raman scattering sensors based on Ag nanoparticles-coated Si nanowire arrays for quantitative detection of pesticides. Appl. Phys. Lett. 2010, 96, 53104. [CrossRef]

2. Harper, M.M.; McKeating, K.S.; Faulds, K. Recent developments and future directions in SERS for bioanalysis. Phys. Chem. Chem. Phys. 2013, 15, 5312. [CrossRef] [PubMed]

3. Feng, Y.; Mo, R.; Wang, L.; Zhou, C.; Hong, P.; Li, C. Surface Enhanced Raman Spectroscopy Detection of Sodium Thiocyanate in Milk Based on the Aggregation of Ag Nanoparticles. Sensors 2019, 19, 1363. [CrossRef] [PubMed]

4. Zhou, Q.; Zhang, X.; Huang, Y.; Li, Z.; Zhang, Z. Rapid Detection of Polychlorinated Biphenyls at Trace Levels in Real Environmental Samples by Surface-Enhanced Raman Scattering. Sensors 2011, 11, 10851-10858. [CrossRef] [PubMed]

5. Granger, J.H.; Schlotter, N.E.; Crawford, A.C.; Porter, M.D. Prospects for point-of-care pathogen diagnostics using surface-enhanced Raman scattering (SERS). Chem. Soc. Rev. 2016, 45, 3865-3882. [CrossRef]

6. Chen, C.; Liu, W.; Tian, S.; Hong, T. Novel Surface-Enhanced Raman Spectroscopy Techniques for DNA, Protein and Drug Detection. Sensors 2019, 19, 1712. [CrossRef] [PubMed]

7. Panneerselvam, R.; Liu, G.K.; Wang, Y.H.; Liu, J.Y.; Ding, S.Y.; Li, J.F.; Wu, D.Y.; Tian, Z.Q. Surface-enhanced Raman spectroscopy: Bottlenecks and future directions. Chem. Commun. 2017, 54, 10-25. [CrossRef]

8. Wijesuriya, S.; Burugapalli, K.; Mackay, R.; Ajaezi, G.C.; Balachandran, W. Chemically Roughened Solid Silver: A Simple, Robust and Broadband SERS Substrate. Sensors 2016, 16, 1742. [CrossRef]

9. Chaney, S.B.; Shanmukh, S.; Dluhy, R.A.; Zhao, Y.-P. Aligned silver nanorod arrays produce high sensitivity surface-enhanced Raman spectroscopy substrates. Appl. Phys. Lett. 2005, 87, 31908. [CrossRef]

10. Wang, H.-H.; Liu, C.-Y.; Wu, S.-B.; Liu, N.-W.; Peng, C.-Y.; Chan, T.-H.; Hsu, C.-F.; Wang, J.-K.; Wang, Y.-L. Highly Raman-Enhancing Substrates Based on Silver Nanoparticle Arrays with Tunable Sub-10nm Gaps. Adv. Mater. 2006, 18, 491-495. [CrossRef]

11. Lee, S.J.; Morrill, A.R.; Moskovits, M. Supporting information to Hot spots in silver nanowire bundles for surface-enhanced Raman spectroscopy. J. Am. Chem. Soc. 2006, 128, 2200-2201. [CrossRef] [PubMed]

12. Huang, Z.; Meng, G.; Huang, Q.; Chen, B.; Zhu, C.; Zhang, Z. Large-area Ag nanorod array substrates for SERS: AAO template-assisted fabrication, functionalization, and application in detection PCBs. J. Raman Spectrosc. 2013, 44, 240-246. [CrossRef]

13. Dinish, U.S.; Agarwal, A.; Yaw, F.C.; Olivo, M.; Champion, P.M.; Ziegler, L.D. Comparison of the Performance of SERS Substrates Fabricated by Deep UV Lithography and Nanosphere Lithography. AIP Conf. Proc. 2010, $1267,956$.

14. Yang, H.; Jiang, P. Large-Scale Colloidal Self-Assembly by Doctor Blade Coating. Langmuir 2010, 26, 13173-13182. [CrossRef] [PubMed]

15. Lin, T.-H.; Linn, N.C.; Tarajano, L.; Jiang, B.; Jiang, P. Electrochemical SERS at Periodic Metallic Nanopyramid Arrays. J. Phys. Chem. C 2009, 113, 1367-1372. [CrossRef]

16. Rochholz, H.; Bocchio, N.; Kreiter, M. Tuning resonances on crescent-shaped noble-metal nanoparticles. New J. Phys. 2007, 9, 53. [CrossRef]

17. Hanarp, P.; Käll, M.; Sutherland, D.S. Optical Properties of Short Range Ordered Arrays of Nanometer Gold Disks Prepared by Colloidal Lithography. J. Phys. Chem. B 2003, 107, 5768-5772. [CrossRef]

18. Wang, C.; Wu, X.; Di, D.; Dong, P.; Xiao, R. Orientation-dependent nanostructure arrays based on anisotropic silicon wet-etching for repeatable surface-enhanced Raman scattering. Nanoscale 2016, 8, 4672-4680. [CrossRef]

19. Liu, X.; Sun, C.-H.; Linn, N.C.; Jiang, B.; Jiang, P. Wafer-Scale Surface-Enhanced Raman Scattering Substrates with Highly Reproducible Enhancement. J. Phys. Chem. C 2009, 113, 14804-14811. [CrossRef]

20. Willets, K.A.; Van Duyne, R.P. Localized Surface Plasmon Resonance Spectroscopy and Sensing. Annu. Rev. Phys. Chem. 2006, 58, 267-297. [CrossRef]

21. Lu, Y.; Liu, G.L.; Kim, J.; Mejia, Y.X.; Lee, L.P. Nanophotonic Crescent Moon Structures with Sharp Edge for Ultrasensitive Biomolecular Detection by Local Electromagnetic Field Enhancement Effect. Nano Lett. 2017, 17, 1648-1654. [CrossRef] [PubMed] 
22. Linn, N.C.; Sun, C.-H.; Arya, A.; Jiang, P.; Jiang, B. Surface-enhanced Raman scattering on periodic metal nanotips with tunable sharpness. Nanotechnology 2009, 20, 225303. [CrossRef] [PubMed]

23. Zhang, X.; Yonzon, C.R.; Van Duyne, R.P. Nanosphere lithography fabricated plasmonic materials and their applications. J. Mater. Res. 2006, 21, 1083-1092. [CrossRef]

24. Kosiorek, A.; Kandulski, W.; Glaczynska, H.; Giersig, M. Fabrication of Nanoscale Rings, Dots, and Rods by Combining Shadow Nanosphere Lithography and Annealed Polystyrene Nanosphere Masks. Small 2005, 1, 439-444. [CrossRef]

25. Fu, C.Y.; Agarwal, A.; Thoniyot, P.; Olivo, M. Glucose sensing using 3D array of reproducible surface enhanced Raman scattering substrates. SPIE NanoSci. Eng. 2009, 7397, 73970.

26. Kosiorek, A.; Kandulski, W.; Chudzinski, P.; Kempa, K.; Giersig, M. Shadow Nanosphere Lithography: Simulation and Experiment. Nano Lett. 2004, 4, 1359-1363. [CrossRef]

27. Lai, Y.-C.; Ho, H.-C.; Shih, B.-W.; Tsai, F.-Y.; Hsueh, C.-H. High performance and reusable SERS substrates using Ag/ZnO heterostructure on periodic silicon nanotube substrate. Appl. Surf. Sci. 2018, 439, 852-858. [CrossRef]

28. Perry, H.; Gopinath, A.; Kaplan, D.L.; Negro, L.D.; Omenetto, F.G. Nano- and Micropatterning of Optically Transparent, Mechanically Robust, Biocompatible Silk Fibroin Films. Adv. Mater. 2008, 20, 3070-3072. [CrossRef]

29. Gunnarsson, L.; Bjerneld, E.J.; Xu, H.; Petronis, S.; Kasemo, B.; Käll, M. Interparticle coupling effects in nanofabricated substrates for surface-enhanced Raman scattering. Appl. Phys. Lett. 2001, 78, 802-804. [CrossRef]

30. Brodsky, J.L.; Andrews, D.W. Robust, Reproducible, Recyclable SERS Substrates: Monolayers of Gold NanoStars grafted on glass and coated with a thin silica layer. Nanotechnology 2011, 30, 118917-118940.

31. Daniels, J.K.; Chumanov, G. Nanoparticle-Mirror Sandwich Substrates for Surface-Enhanced Raman Scattering. J. Phys. Chem. B 2005, 109, 17936-17942. [CrossRef] [PubMed]

32. Lee, Y.H.; Shi, W.; Lee, H.K.; Jiang, R.; Phang, I.Y.; Cui, Y.; Isa, L.; Yang, Y.; Wang, J.; Li, S.; et al. Nanoscale surface chemistry directs the tunable assembly of silver octahedra into three two-dimensional plasmonic superlattices. Nat. Commun. 2015, 6, 6990. [CrossRef] [PubMed]

33. Mulvihill, M.; Tao, A.; Benjauthrit, K.; Arnold, J.; Yang, P. Surface-Enhanced Raman Spectroscopy for Trace Arsenic Detection in Contaminated Water. Angew. Chem. Int. Ed. 2008, 47, 6456-6460. [CrossRef] [PubMed]

34. Ngo, Y.H.; Li, D.; Simon, G.P.; Garnier, G. Effect of cationic polyacrylamides on the aggregation and SERS performance of gold nanoparticles-treated paper. J. Colloid Interface Sci. 2013, 392, 237-246. [CrossRef] [PubMed]

35. Yap, F.L.; Thoniyot, P.; Krishnan, S.; Krishnamoorthy, S. Nanoparticle Cluster Arrays for High-Performance SERS through Directed Self-Assembly on Flat Substrates and on Optical Fibers. ACS Nano 2012, 6, 2056-2070. [CrossRef] [PubMed]

36. Zhang, L. Self-assembly Ag nanoparticle monolayer film as SERS Substrate for pesticide detection. Appl. Surf. Sci. 2013, 270, 292-294. [CrossRef]

37. Zhong, L.-B.; Yin, J.; Zheng, Y.-M.; Liu, Q.; Cheng, X.-X.; Luo, F.-H. Self-Assembly of Au Nanoparticles on PMMA Template as Flexible, Transparent, and Highly Active SERS Substrates. Anal. Chem. 2014, 86, 6262-6267. [CrossRef]

38. Šubr, M.; Petr, M.; Peksa, V.; Kylián, O.; Hanuš, J.; Procházka, M. Ag Nanorod Arrays for SERS: Aspects of Spectral Reproducibility, Surface Contamination, and Spectral Sensitivity. J. Nanomater. 2015, 2015, 1-7. [CrossRef]

39. Oh, Y.-J.; Kang, M.; Park, M.; Jeong, K.-H. Engineering hot spots on plasmonic nanopillar arrays for SERS: A review. BioChip J. 2016, 10, 297-309. [CrossRef]

40. Kumar, S.; Lodhi, D.K.; Goel, P.; Kalyani, N.; Mishra, P.; Singh, J.P. Neeti A facile method for fabrication of buckled PDMS silver nanorod arrays as active 3D SERS cages for bacterial sensing. Chem. Commun. 2015, 51, 12411-12414. [CrossRef]

41. Liu, Y.-J.; Chu, H.Y.; Zhao, Y.-P. Silver Nanorod Array Substrates Fabricated by Oblique Angle Deposition: Morphological, Optical, and SERS Characterizations. J. Phys. Chem. C 2010, 114, 8176-8183. [CrossRef]

42. Zhao, Y.-P.; Chaney, S.B.; Shanmukh, S.; Dluhy, R.A. Polarized Surface Enhanced Raman and Absorbance Spectra of Aligned Silver Nanorod Arrays. J. Phys. Chem. B 2006, 110, 3153-3157. [CrossRef] [PubMed] 
43. Blackwell, R.; Zhao, Y.-P. Metal nanoparticle embedded porous thin films prepared by oblique angle coevaporation. J. Vac. Sci. Technol. B Microelectron. Nanometer Struct. 2008, 26, 1344. [CrossRef]

44. Ma, L.; Huang, Y.; Hou, M.; Xie, Z.; Zhang, Z. Silver Nanorods Wrapped with Ultrathin Al2O3 Layers Exhibiting Excellent SERS Sensitivity and Outstanding SERS Stability. Sci. Rep. 2015, 5, 12890. [CrossRef] [PubMed]

45. Limnonthakul, P.; Limwichean, S.; Eiamchai, P.; Horprathum, M.; Supati, A.; Nuntawong, N.; Patthanasetakul, V.; Chindaudom, P.; Supatti, A. Vertically Aligned Ag Nanorod Arrays for Trace Cypermethrin Detection. Adv. Mater. Res. 2014, 979, 259-262. [CrossRef]

46. Beavers, K.R.; Marotta, N.E.; Bottomley, L.A. Thermal Stability of Silver Nanorod Arrays. Chem. Mater. 2010, 22, 2184-2189. [CrossRef]

47. Chu, H.O.; Song, S.; Li, C.; Gibson, D. Surface Enhanced Raman Scattering Substrates Made by Oblique Angle Deposition: Methods and Applications. Coatings 2017, 7, 26. [CrossRef]

48. Singh, J.P.; Lanier, T.E.; Zhu, H.; Dennis, W.M.; Tripp, R.A.; Zhao, Y. Highly Sensitive and Transparent Surface Enhanced Raman Scattering Substrates Made by Active Coldly Condensed Ag Nanorod Arrays. J. Phys. Chem. C 2012, 116, 20550-20557. [CrossRef]

49. Oh, M.-K.; Shin, Y.-S.; Lee, C.-L.; De, R.; Kang, H.; Yu, N.E.; Kim, B.H.; Kim, J.H.; Yang, J.-K. Morphological and SERS Properties of Silver Nanorod Array Films Fabricated by Oblique Thermal Evaporation at Various Substrate Temperatures. Nanoscale Res. Lett. 2015, 10, 737. [CrossRef]

50. He, Z.; Kretzschmar, I. Template-Assisted GLAD: Approach to Single and Multipatch Patchy Particles with Controlled Patch Shape. Langmuir 2013, 29, 15755-15761. [CrossRef]

51. Ingram, W.M.; Han, C.; Zhang, Q.; Zhao, Y. Optimization of Ag-Coated Polystyrene Nanosphere Substrates for Quantitative Surface-Enhanced Raman Spectroscopy Analysis. J. Phys. Chem. C 2015, 119, 27639-27648. [CrossRef]

52. Keating, M.; Song, S.; Wei, G.; Graham, D.; Chen, Y.; Placido, F. Ordered silver and copper nanorod arrays for enhanced Raman scattering created via guided oblique angle deposition on polymer. J. Phys. Chem. C 2014, 118, 4878-4884. [CrossRef]

53. Stoddart, P.R.; Jayawardhana, S. Nanofabrication of surface-enhanced Raman scattering substrates for optical fiber sensors. Spie Moems-Mems 2013, 8613, 86130.

54. Suzuki, M.; Nakajima, K.; Kimura, K.; Fukuoka, T.; Mori, Y. Au nanorod arrays tailored for surface-enhanced Raman spectroscopy. Anal. Sci. 2007, 23, 829-833. [CrossRef] [PubMed]

55. Fan, J.-G.; Zhao, Y.-P. Gold-Coated Nanorod Arrays as Highly Sensitive Substrates for Surface-Enhanced Raman Spectroscopy. Langmuir 2008, 24, 14172-14175. [CrossRef] [PubMed]

56. Jen, Y.-J.; Chan, S.; Huang, J.-W.; Jheng, C.-Y.; Liu, W.-C. Self-Shadowing Deposited Pure Metal Nanohelix Arrays and SERS Application. Nanoscale Res. Lett. 2015, 10, 247401. [CrossRef] [PubMed]

57. Jen, Y.-J.; Huang, J.-W.; Liu, W.-C.; Chan, S.; Tseng, C.-H. Glancing angle deposited gold nanohelix arrays on smooth glass as three-dimensional SERS substrates. Opt. Mater. Express 2016, 6, 697. [CrossRef]

58. Dikovska, A.O.; Avdeev, G.V.; Nedyalkov, N.N.; Koleva, M.E.; Atanasov, P.A. Preparation of metal nanorods substrates for SERS application. In Proceedings of the Seventeenth International School on Quantum Electronics: Laser Physics and Applications, Nessebar, Bulgaria, 24-28 September 2012; Volume 8770, p. 877006 .

59. Tang, X.; Zhao, Y.; Dluhy, R.A. The use of aligned silver nanorod arrays prepared by oblique angle deposition as surface enhanced Raman scattering substrates. J. Phys. Chem. C 2008, 112, 895-901.

60. Liu, Y.-J.; Zhao, Y.-P. Simple model for surface-enhanced Raman scattering from tilted silver nanorod array substrates. Phys. Rev. B 2008, 78, 1-9. [CrossRef]

61. Meyer, M.R.; Wilhelm, J.; Peters, F.T.; Maurer, H.H. Beta-keto amphetamines: Studies on the metabolism of the designer drug mephedrone and toxicological detection of mephedrone, butylone, and methylone in urine using gas chromatography-mass spectrometry. Anal. Bioanal. Chem. 2010, 397, 1225-1233. [CrossRef]

62. Mahoor, N.; Tehrani, M.S.; Givianrad, M.H. Surfactant-assisted dispersive liquid-liquid microextraction followed by high-performance liquid chromatography for determination of amphetamine and methamphetamine in urine samples. Anal. Methods 2012, 4, 1357.

63. Chen, X. Simultaneous determination of four designer drugs and their major metabolites by liquid chromatography-mass spectrometry. J. Chromatogr. B 2015, 992, 1-7. [CrossRef] [PubMed] 
64. Nadulski, T. Utility of ELISA screening for the monitoring of abstinence from illegal and legal drugs in hair and urine. Drug Test. Anal. 2014, 6, 101-109.

65. Van Der Heide, S.; Russell, D.A. Optimisation of immuno-gold nanoparticle complexes for antigen detection. J. Colloid Interface Sci. 2016, 471, 127-135. [CrossRef] [PubMed]

66. Hawkeye, M.M.; Taschuk, M.T.; Brett, M.J. Glancing Angle Deposition of Thin Films: Engineering the Nanoscale; John Wiley \& Sons: Hoboken, NJ, USA, 2014; ISBN 9781118847565.

67. Sikkens, M.; Horowitz, F.; Hodgkinson, I.J.; Macleod, H.A.; Wharton, J.J. Measurement of the principal refractive indices of thin films deposited at oblique incidence. J. Opt. Soc. Am. A 2008, 2, 1693.

68. Lee, J.; Min, K.; Kim, Y.; Yu, H.K.; Ag, A. Surface-Enhanced Raman Spectroscopy (SERS) Study Using Oblique Angle Deposition of Ag Using Different Substrates. Materials 2019, 12, 1581. [CrossRef]

69. Chen, J.; Dong, P.; Wang, C.; Zhang, C.; Wang, J.; Wu, X. Performance Improving Method of Aligned Silver Nanorod by Grafting Au@Ag Core-Shell Nanoparticles for Surface-Enhanced Raman Scattering. Nano 2017, 12, 1750131. [CrossRef]

70. Le Ru, E.C.; Blackie, E.; Meyer, M.; Etchegoin, P.G. Surface Enhanced Raman Scattering Enhancement Factors: A Comprehensive Study. J. Phys. Chem. C 2007, 111, 13794-13803. [CrossRef]

71. Han, C.; Yao, Y.; Wang, W.; Qu, L.; Bradley, L.; Sun, S.; Zhao, Y. Rapid and sensitive detection of sodium saccharin in soft drinks by silver nanorod array SERS substrates. Sens. Actuators B Chem. 2017, 251, 272-279. [CrossRef]

72. Ma, Y.; Liu, H.; Mao, M.; Meng, J.; Yang, L.; Liu, J. Surface-Enhanced Raman Spectroscopy on Liquid Interfacial Nanoparticle Arrays for Multiplex Detecting Drugs in Urine. Anal. Chem. 2016, 88, 8145-8151. [CrossRef] [PubMed]

73. Muehlethaler, C.; Leona, M.; Lombardi, J.R. Towards a validation of surface-enhanced Raman scattering (SERS) for use in forensic science: Repeatability and reproducibility experiments. Forensic Sci. Int. 2016, 268, 1-13. [CrossRef] [PubMed]

(C) 2019 by the authors. Licensee MDPI, Basel, Switzerland. This article is an open access article distributed under the terms and conditions of the Creative Commons Attribution (CC BY) license (http://creativecommons.org/licenses/by/4.0/). 